\title{
Improving oil quality by altering levels of fatty acids through marker-assisted selection of $a h f a d 2$ alleles in peanut (Arachis hypogaea L.)
}

\author{
Sandip K. Bera (D) - Jignesh H. Kamdar (D) Swati V. Kasundra • \\ Pitabas Dash · Anil K. Maurya - Mital D. Jasani - Ajay B. Chandrashekar • \\ N. Manivannan - R. P. Vasanthi - K. L. Dobariya - Manish K. Pandey (D) \\ Pasupuleti Janila • T. Radhakrishnan • Rajeev K. Varshney (i)
}

Received: 4 May 2018/ Accepted: 11 August 2018

(C) Springer Nature B.V. 2018

\begin{abstract}
Peanut plays a key role to the livelihood of millions in the world especially in Arid and Semi-Arid regions. Peanut with high oleic acid content aids to increase shelf-life of peanut oil as well as food products and extends major health benefits to the consumers. In peanut, $a h F A D 2$ gene controls quantity of two major fatty acids viz, oleic and linoleic acids. These two fatty acids together with palmitic acid constitute $90 \%$ fat composition in peanut and regulate the quality of peanut oil. Here, two ahfad 2 alleles from SunOleic 95R were introgressed into ICGV 05141 using marker-assisted selection. Marker-assisted breeding effectively increased oleic acid and oleic to
\end{abstract}

Electronic supplementary material The online version of this article (https://doi.org/10.1007/s10681-018-2241-0) contains supplementary material, which is available to authorized users.

S. K. Bera $(\bowtie)$ J. H. Kamdar · S. V. Kasundra .

P. Dash · A. K. Maurya - M. D. Jasani .

A. B. Chandrashekar · T. Radhakrishnan

Indian Council of Agricultural Research-Directorate of

Groundnut Research (ICAR-DGR), Junagadh, India

e-mail: berask67@yahoo.co.in

N. Manivannan

National Pulses Research Center, Tamil Nadu

Agricultural University (TNAU), Pudukkottai, India

R. P. Vasanthi

Regional Agricultural Research Station, Acharya NG

Ranga Agricultural University (ANGRAU), Tirupati, India linoleic acid ratio in recombinant lines up to $44 \%$ and $30 \%$, respectively as compared to ICGV 05141. In addition to improved oil quality, the recombinant lines also had superiority in pod yield together with desired pod/seed attributes. Realizing the health benefits and ever increasing demand in domestic and international market, the high oleic peanut recombinant lines will certainly boost the economical benefits to the Indian farmers in addition to ensuring availability of high oleic peanuts to the traders and industry.

Keywords Peanut - Oleic acid - Oil quality · Markerassisted selection (MAS) $\cdot a h F A D 2$ gene

\author{
K. L. Dobariya \\ Main Oilseeds Research Station, Junagadh Agricultural \\ University (JAU), Junagadh, India \\ M. K. Pandey · P. Janila · R. K. Varshney \\ International Crops Research Institute for the Semi-Arid \\ Tropics (ICRISAT), Hyderabad, India
}




\section{Introduction}

Peanut (Arachis hypogaea L.) is cultivated in an area of $\sim 25.44 \mathrm{~m}$ ha with a production of $\sim 45.22 \mathrm{~m}$ tons (FAO 2014). Based on average production, the China, India, Nigeria, United States of America and Sudan are top five peanut producing countries in the world which together contribute $\sim 70 \%$ to the global peanut production (FAO 2014). In USA and other European countries, major share of peanut produce ( 75\%) goes towards confectionary and other food purpose, while half of the produce $(\sim 49 \%)$ goes for oil extraction in two major groundnut producing countries viz, China and India. Fatty acid composition defines the peanut oil quality which contains $80 \%$ unsaturated fatty acids (UFA) and 20\% saturated fatty acids (SFA). Oleic and linoleic acids constitute UFA, while palmitic, stearic, arachidic, gadoleic, behenic and lignoceric acids constitute SFA. Palmitic acid alone constitutes about $10 \%$ of SFA, while remaining five fatty acids together constitute remaining $10 \%$ of SFA (Kavera et al. 2014). Together oleic, linoleic and palmitic acids comprise $\sim 90 \%$ of the total fatty acid composition and regulate the quality of peanut oil (Moore and Knauft 1989).

Peanut oil is preferred for cooking purpose due to its higher UFAs to SFAs ratio (Johnson and Saikia 2008). In general SFAs increase serum low-density lipoproteins (LDL) cholesterol level in the blood. Excess consumption of palmitic acid increases the risk of cardiovascular diseases (CVD) (WHO 2003). On the other hand higher linoleic acid in oil helps in oxidative rancidity and oil becomes thermodynamically unstable upon heating (Kratz et al. 2002). Furthermore, variation in linoleic acid content promotes formation of trans-fatty acid which also causes CVD. In contrast, high oleic acid content in cooking oil decreases the risk of CVD by reducing the level of serum LDL cholesterol and maintains level of highdensity lipoproteins (HDL) (Rizzo et al. 1986; Wang 2009; Vassiliou et al. 2009). Besides, consumption of peanut products rich in oleic acid decreases tumorigenesis, and ameliorate inflammatory diseases (O'Byrne et al. 1997; Yamaki et al. 2005). Oleic acid has 10-fold higher auto-oxidative stability than linoleic acid (O'Keefe et al. 1993). Thus, peanut and its byproducts with high oleic acid as well as high oleic to linoleic acid ratio (O/L ratio) have longer shelf life than normal peanut (Mozingo et al. 2004). Therefore, breeding peanut varieties with high oleic acid and reduced level of linoleic and palmitic acids are essential to make peanut nutritionally more desirable to the consumers (Janila et al. 2016). Availability of F435, a peanut mutant with $80 \%$ oleic acid and $2 \%$ linoleic acid contents, helped in breeding high oleic peanuts, SunOleic 95R followed by SunOleic 97R in USA (Norden et al. 1987). Previous studies have reported that two alleles each in the A-genome $(a h F A D 2 A)$ and in the B-genome (ahFAD2B) control fatty acids contents in peanut (Wang et al. 2013, 2015a). Subsequently, Chu et al. (2009) and Chen et al. (2010) developed linked cleaved amplified polymorphic sequence (CAPS) and allele-specific markers, respectively for both ahFAD2A and $a h F A D 2 B$ alleles. Associated CAPS markers to high oleic acid in peanut helped to breed 'Tifguard High O/L' variety in USA (Chu et al. 2007). Recently, Janila et al. (2016) developed high oleic peanuts using both AS-PCR and CAPS markers. Here we used both AS-PCR and CAPS markers for breeding high oleic recombinants of ICGV 05141. The female parent, ICGV 05141 used here is different from Janila et al. (2016) and has high pod and oil yield together with desirable pod and seed features. High oleic peanut recombinant lines bred here are of different genetic background and under large-scale yield trials which would be released soon for cultivation to the Indian peanut farmers.

\section{Materials and methods}

\section{Plant material}

The ICGV 05141, a Virginia bunch genotype (A. hypogaea ssp. hypogaea var. hypogaea), is derived from the cross $\{\{[($ Robut 33-1 $\times$ NC Ac 316) $\times$ (Robut 33-1 × CS 9)] $\times$ ICGV 93023\} $\times$ ICGV 99160\}. ICGV 05141, a high oil (55.1\%) and normal oleic acid content $(55.8 \%)$ peanut breeding line was used as female parent. ICGV 05141 is one of the 52 high oil containing peanut breeding line developed by ICRISAT and tested for yield at ICAR-Directorate of Groundnut Research (ICAR-DGR), Junagadh, Gujarat over four seasons. Pod yield of ICGV 05141 was $2672 \mathrm{~kg} / \mathrm{ha}$ and $2416 \mathrm{~kg} / \mathrm{ha}$ during 2011 rainy and 2012 rainy seasons, respectively. While, in 2011 post rainy and 2012 post rainy seasons pod yield was 
$1486 \mathrm{~kg} / \mathrm{ha}$ and $1875 \mathrm{~kg} / \mathrm{ha}$, respectively (Project report, 'Development and promotion of....Groundnut farmers in India' ICRISAT, 2012; unpublished). The SunOleic 95R was used as male parent which contains $a h f a d 2 a$ and $a h f a d 2 b$ alleles and characterized with low oil (45\%) and high oleic acid ( 80\%) containing line. The SunOleic 95R was bred using F435 mutant at Florida Experimental Agriculture Station, USA and was characterized as a Virginia runner peanut (Gorbet and Knauft 1997). However, in our experiment we found Virginia bunch growth habit in SunOleic 95R.

Molecular markers

Breeding population in early generations $\left(\mathrm{F}_{1}\right.$ and $\left.\mathrm{F}_{2}\right)$ was screened with two types of markers linked to $a h F A D 2$ gene. Plants with wild or mutant alleles were identified using the allele specific-polymerase chain reaction (AS-PCR) markers (Chen et al. 2010). While, plants with homozygous or heterozygous alleles were identified using the cleaved amplified polymorphic sequences (CAPS) markers (Chu et al. 2009) (Supplementary Table).

DNA extraction and marker genotyping

Tender leaf samples from 10 to 15 days old seedlings were collected. The DNA was extracted from the leaf samples of ICGV 05141, SunOleic 95R and segregating progenies using modified cetyltrimethyl ammonium bromide (CTAB) extraction method (Mace et al. 2003). The quality of DNA was tested on $0.8 \%$ agarose gel (Lonza, USA). The concentration of DNA was checked in ND100 Spectrophotometer (Nano Drop Technology, USA) and later concentration was normalized to $\sim 100 \mathrm{ng} / \mu \mathrm{l}$ for downstream application.

\section{Genotyping with allele specific-polymerase chain reaction markers}

Amplification of $a h f a d 2 a$ and $a h f a d 2 b$ alleles were checked using two different primer pairs, while a separate primer pair was used to amplify $a h F A D 2 A$ or ahFAD2B alleles (Chen et al. 2010). In case of mutant allele (substitution from $\mathrm{G}: \mathrm{C} \rightarrow \mathrm{A}: \mathrm{T}$ ) in the A-genome the primer combination, F435-F and F435SUB-R amplified a 203 bp fragment, while in case of mutant allele (A:T insertion) in the B-genome the primer combination, F435-F and F435INS-R amplified a $195 \mathrm{bp}$ fragment. For wild type allele, the primer combination, F435-F and F435WT-R amplified a 193 bp fragment. F435-F and F435IC-R, amplified a $250 \mathrm{bp}$ fragment and used as internal control to confirm successful amplification of alleles. The polymerase chain reaction (PCR) for AS-PCR markers was carried out in C1000 Thermal cycler (BIO-RAD, USA). The PCR reaction was setup in $25 \mu 1$ volume using the protocol of KAPA3G Plant PCR Kit (KK7251, Kapa Biosystems, USA). Amplification of PCR assay was done using protocol as mentioned in Janila et al. (2016). The amplified DNA fragments along with 100 bp DNA marker (Thermo Scientific, USA) were size separated on a $2.0 \%$ horizontal agarose gel (Lonza, USA). Gel electrophoresis was carried out in $1 \mathrm{X}$ TBE buffer at $100 \mathrm{~V}$ current for one to two hours. The Ethidium bromide was used for staining the DNA fragments and gel was scanned using laser scanner (Fujifilm FLA 5100, Japan) for scoring.

\section{Genotyping with CAPS markers}

The PCR amplification was carried out in BIO-RAD C1000 Thermal cycler. For amplification of ahFAD2A/ahfad2a alleles the primer pairs aF19F and 1056R (IDT, USA) were used. Amplified product was further digested with Hpy99I (New England Bio Labs, UK) restriction enzyme having single recognition site to detect $448 \mathrm{G} \rightarrow$ A mutation. Similarly, the primers bF19F and R1/FADR (IDT, USA) were used to detect insertion mutation (insertion of single base 'A') at 441_442 bp in the ahFAD2B/ahfad2b alleles. The PCR reaction was setup in $25 \mu$ volume using the protocol of KAPA3G Plant PCR Kit (KK7251, Kapa Biosystems, USA). Amplification of PCR assay was done using protocol as mentioned in Janila et al. (2016) and Chu et al. (2009). The PCR product was resolved on $2 \%$ agarose gel for confirming the amplification and digested with restriction enzyme after purification. Restriction digestion of the $10 \mu \mathrm{l}$ of A-genome amplicon was done using $0.5 \mathrm{U}$ of restriction enzyme Hpy99I (New England Biolabs, UK) by incubating at $37{ }^{\circ} \mathrm{C}$ for about $4 \mathrm{~h}$. In case of $a h F A D 2 A$ allele, the $826 \mathrm{bp}$ fragment was digested to $598 \mathrm{bp}$ and $228 \mathrm{bp}$, while ahfad $2 a$ allele had the 826 bp fragment intact. On the other hand, the restriction digestion of $10 \mu \mathrm{l}$ of B-genome amplicon was done using $2.0 \mathrm{U}$ of 
restriction enzyme Hpy188I (New England Biolabs, UK) by incubating about $16 \mathrm{~h}$ at $37{ }^{\circ} \mathrm{C}$. The $1214 \mathrm{bp}$ $a h F A D 2 B$ allele having five restriction sites cleaved into five fragments i.e., 736, 263, 171, 32 and $12 \mathrm{bp}$. While in case of ahfad $2 b$ allele, the $736 \mathrm{bp}$ fragment had one additional restriction site which further cleaved into 550 and $213 \mathrm{bp}$. Thus, ahfad $2 b$ allele produced six fragments instead of five in case of $a h F A D 2 B$ allele.

Back ground testing of recombinant lines was done with nine simple sequence repeat markers (SSRs). Nine SSRs (Supplementary Data) were picked up within the $20 \mathrm{cM}$ of $a h F A D 2$ loci (Gautami et al. 2012). SSRs analysis was done in female parent and 11 recombinant lines (HOP-IL_MAs-108, HOP-IL_MAS111, HOP-IL_MAS 119, HOP-IL_MAS -120 , HOPIL_MAS-130, HOP-IL_MAS-154, HOP-IL_MAS-181, HOP-IL_MAS-201, HOP-IL_MAS-123, HOP-IL_MAS144, and HOP-IL_MAs-171). Recombinant lines used in background testing were selected based on existing DNA samples in the lab. Amplification of PCR assay was done using protocol as mentioned in Bera et al. (2016). The PCR product was resolved on $2 \%$ agarose gel and was scanned using laser scanner (Fujifilm FLA 5100, Japan).

Hybridization and development of MAS lines

Hybridization was done at ICRISAT, Patancharu, Telangana, India during 2011 rainy season. The $F_{1} \mathrm{~s}$ were planted in pots kept inside net-house at ICARDGR, Junagadh, India during 2011 post rainy season. Individual $F_{1}$ plants were tagged and genotyped with allele specific markers. The $\mathrm{F}_{1}$ plants having double mutant alleles were selfed and harvested single plant basis. $F_{2}$ onwards plants were planted in open field of ICAR-DGR.

A total of $204 \mathrm{~F}_{2}$ plants were planted in 2012 rainy season and were genotyped with allele specific markers to identify double mutant lines. Further double mutant lines were genotyped using CAPS markers to select homozygous double mutant lines. Homozygous double mutant lines were further advanced to next generations during 2012 post rainy season. A total of 21 homozygous double mutant single plant progenies were advanced to $\mathrm{F}_{4}$ generation in 2013 rainy season and subsequently phenotyped for oil content, protein content and fatty acid profile. Phenotyping for oil, protein and fatty acid profile was repeated for entire 21 lines in $\mathrm{F}_{5}$ generation in 2013 post rainy season.

\section{Field evaluation}

Selected high oleic recombinant lines were compared with female parent and elite cultivar for yield and its related traits in 2014 rainy $\left(\mathrm{F}_{6}\right)$ and 2015 rainy $\left(\mathrm{F}_{7}\right)$ seasons. Recombinant lines, 21 in numbers, together with female parent (ICGV 05141) and an elite cultivar (GG 20) were planted in the farm of ICAR-DGR, Junagadh. Sowing of experiment was done in randomized block design (RBD) with three replications in second week of June 2014 and harvested in last week of October 2014. Each genotype was planted in four lines on four-metre beds. Line to line and plant to plant spacing were 45 and $10 \mathrm{~cm}$, respectively. Recommended local crop management practices were followed for raising a healthy crop. Pod yield per plot (plot size was $7.2 \mathrm{~m}^{2}$ ) was recorded at harvest. The experiment was repeated in 2015 rainy season following experimental design and crop management practices of previous season.

\section{Characterization of genotype}

Recombinant lines and ICGV 05141 were characterized based on 16 qualitative, 17 quantitative and two special features following peanut-descriptor (International Board for Plant Genetic Resources (IBPGR) and International Crops Research Institute for the SemiArid Tropics (ICRISAT) 1992) from five plant samples collected from field at vegetative, reproductive and harvesting stages.

Biochemical analysis for oil content and fatty acids

Sound matured kernels (10-15 g) harvested from $\mathrm{F}_{3-4}$ and $\mathrm{F}_{4-5}$ progenies were used for both oil content and fatty acid analysis. The fatty acid composition and oil content were estimated using Gas chromatography (GC 700, Thermo Fisher, USA) with flame ionization detector (FID). For estimation of the esters of fatty acids the fatty acid methyl esters were passed through capillary column (TR-wax) (Misra and Mathur 1998). The FID detector was set to $240{ }^{\circ} \mathrm{C}$ and oven at $190{ }^{\circ} \mathrm{C}$. Carrier gas (nitrogen) and fuel gas (hydrogen) were maintained at $30 \mathrm{ml}$ per min. Each sample was run for $12 \mathrm{~min}$ and the peaks were identified by 
comparison to a FAME standard mix RM-3 (SigmaAldrich, St. Louis, MO).

Statistical analysis

Mean differences among genotypes were done using Cropstat version 7.2 (IRRI 2007).

\section{Results}

Development of MAS progenies

Cross-seed, 11 in numbers, from a cross between ICGV 05141 and SunOleic 95R were collected from ICRISAT, Patancheru and were planted at ICARDGR, Junagadh. Upon genotyping of $F_{1}$ s, eight plants with $a h f a d 2 a$ and $a h f a d 2 b$ alleles were identified. Here after, plants carrying both $a h f a d 2 a$ and $a h f a d 2 b$ alleles shall be referred as double mutant plant(s). All eight double mutant plants were selfed and advanced to $F_{2}$ generation.

A total of $204 \mathrm{~F}_{2}$ plants were grown and genotyped with allele-specific and CAPS markers (Figs. 1,2). Of these, 21 plants were homozygous double mutant plants and were selfed from $F_{3}$ generation to $F_{5}$ generation. Upon phenotyping for oil and oleic acid content consecutively for two years 21 recombinant lines with high oil and oleic acid content were selected. Selected recombinant lines and female parent were further screened with nine SSRs for selecting ideal recombinants. Out of which PM-170, AC3C07, TC5D06, Seq4G02, Seq7G02, GM2120, GM1893 markers amplified both in female parent and majority of the recombinant lines revealing transfer of the genomic region adjacent to ahFAD2 loci from ICGV 05141 to the recombinant lines (Fig. 3).

Oil protein and fatty acid analysis

of recombinant lines and their parents

A significant variation in oil content was observed among the recombinant lines and their parents which ranged from 49.7 to $57.9 \%$ with an average of $53.3 \%$ during 2013 rainy season (Table 1). Oil content in majority of the recombinant lines was at par with the female parent except HOP-IL_MAs-116, HOPIL_MAS-120 and HOP-IL_MAS-172 which had 49.7, 50.5 and $50.9 \%$ of oil, respectively. During 2013 post rainy season, oil content ranged from 45.0 to $57.6 \%$ with an average of $53.0 \%$ (Table 1). Unlike 2013 rainy season, majority of recombinant lines were at par with the female parent except HOP-IL_MAs-116, HOPIL_MAs-119, HOP-IL_MAS-172 and HOP-IL_MAs-201 which had 49.3, 46.2, 45.0 and $46.3 \%$ of oil, respectively. All the recombinant lines had oil content at par with female parent except HOP-IL_MAs-116 and HOP-IL_MAs-172 which had $49.5 \%$ and $48.0 \%$ of oil, respectively. Pooled protein content in ICGV 05141 and SunOleic 95R were 25\% and 26\%, respectively. Nevertheless, a significant variation was observed for protein content among recombinant lines which varied from 21.25 to $25.01 \%$ (Table 1 ). ICGV 05141 had $55.7 \%$ oleic acid, 23\% linoleic acid and $10.8 \%$ palmitic acid, while SunOleic 95R had $78.8 \%$ oleic acid, $3.7 \%$ linoleic acid and $7.6 \%$ palmitic acid. Oleic acid content in recombinant lines ranged from 57.8 to $80.5 \%$ during 2013 rainy season. While, in 2013 post rainy season, it varied from 55.6 to $82.0 \%$ (Figs. 4, 5). Stable quantity of oleic acid content in

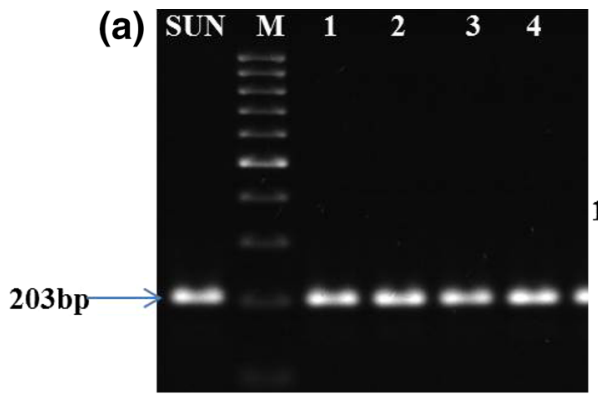

Fig. 1 AS-PCR assay; a Showing amplification of ahfad $2 a$ allele specific 203 bp fragmentin 1 to $4 F_{1}$ plants b Amplification of $a h f a d 2 b$ allele specific $195 \mathrm{bp}$ fragment in 3 and 4 ,

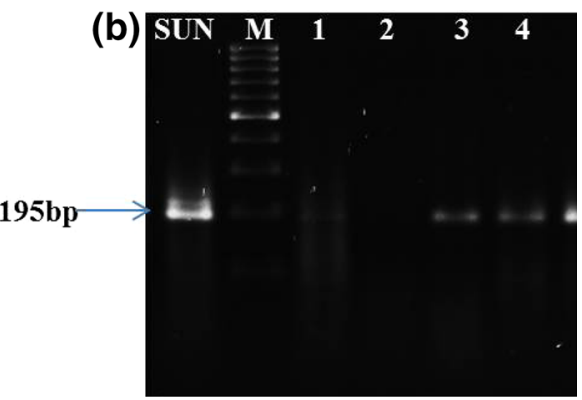

while absent in 1 and $2 F_{1}$ plants; Where SUN: SunOleic 95R, M:100 bp DNA ladder 
Fig. 2 CAPS assay; a Showing heterozygous and homozygous plants for ahfad $2 a$ allele. b Showing heterozygous and homozygous plants for $a h f a d 2 b$ mutant allele. Where SUN: SunOleic 95R, M: 100 bp DNA ladder, CO: Control, 'AA, BB': homozygous wild alleles, 'Aa, Bb': heterozygous alleles and 'aa, bb': indicates homozygous mutant alleles
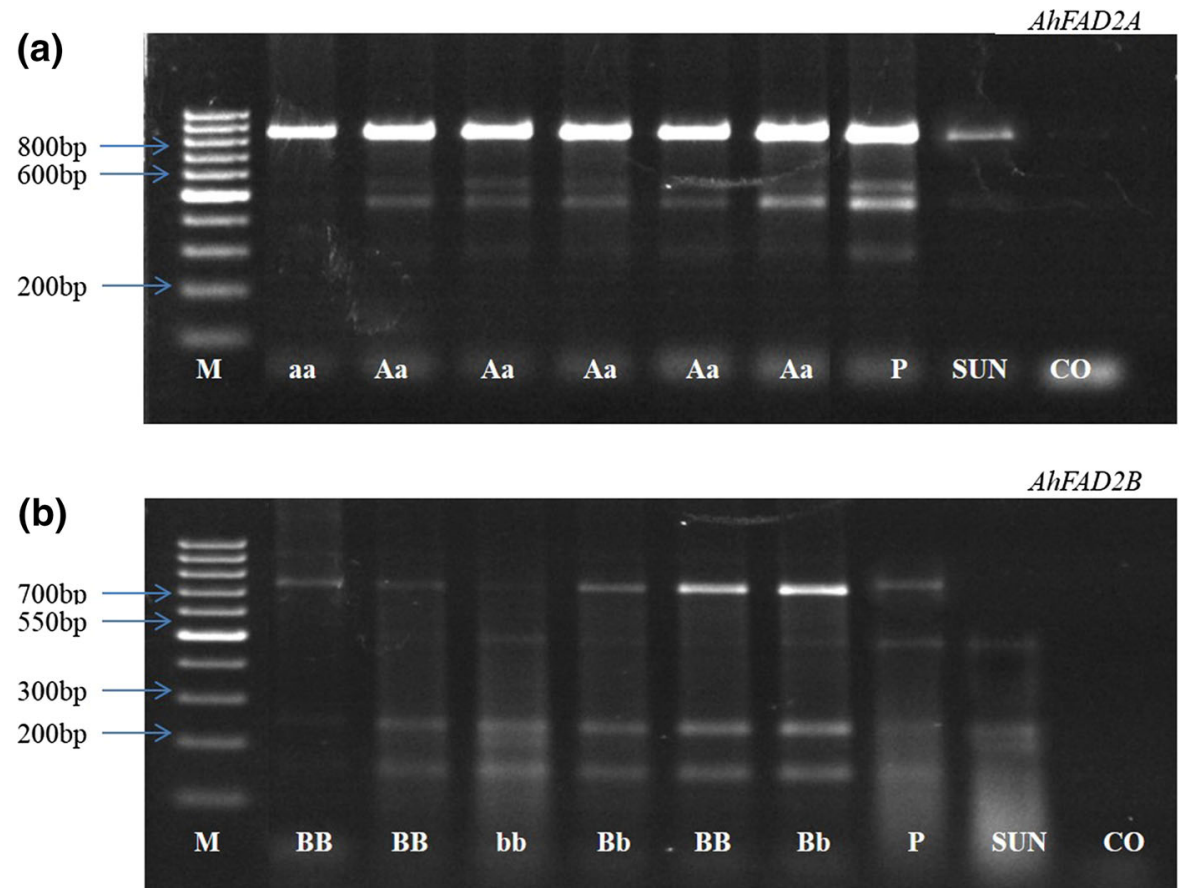

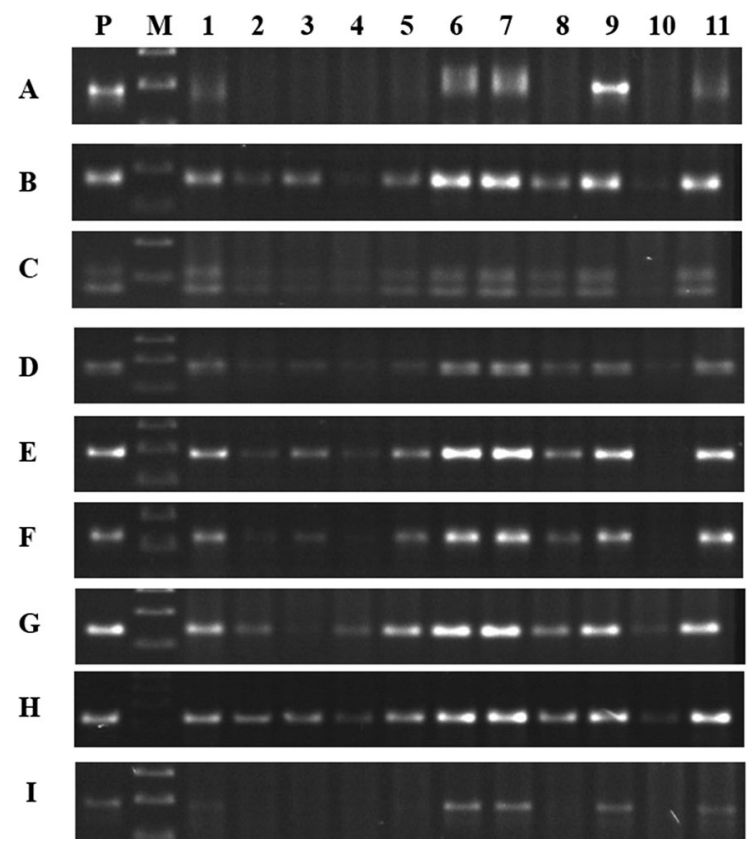

Fig. 3 SSR assisted background selection, Where A—gi-1107, B-PM-170, C-AC3C07, D-TC5D06, E-Seq 4G02, FSeq 7G02, G-GM2120, H-GM1893, I-Seq 17C09. PICGV 05141, M-100 bp ladder, 1 to $11-$ Recombinant lines

both the seasons was noticed in majority of the recombinant lines, while it varied marginally in a few of them including SunOleic 95R over seasons. Based on oleic acid content pooled over two seasons, majority of the recombinant lines had $>70 \%$ oleic acid except HOP-IL_MAs-123, HOP-IL_MAS ${ }^{-144}$, HOP-IL_MAS-164, HOP-Il_MAs-166 and HOPIL_MAS-171 which had 61.0, 58.3, 56.7, 63.8 and $69.1 \%$ of oleic acid, respectively (Fig. 6). Wide range of variation for linoleic acid content was observed among recombinant lines during both 2013 rainy season and 2013 post rainy season. It varied from 2.3 to $21.6 \%$ in rainy season while from 2.2 to $24 \%$ in post rainy season. Indeed, majority of recombinant lines had $<10 \%$ linoleic acid (average of two seasons) except HOP-IL_MAs-123, HOP-IL_MAs-144, HOPIL_MAs-164, HOP-IL_MAs-166 and HOP-IL_MAs -171 which had $19.4 \%, 21.45 \%, 22.8 \% 16.9 \%$ and $12.25 \%$ of linoleic acid, respectively. Similar to oleic acid, linoleic acid content also differed between seasons in a few recombinant lines. While, linoleic acid content in ICGV 05141 and GG 20 remained almost stable between seasons. Besides, lower and comparatively stable linoleic acid content was observed in 10 recombinant lines irrespective of seasons (Table 2). In case of palmitic acid, marginal variation was observed in recombinant lines, irrespective of seasons. Over all, palmitic acid, pooled over two seasons, varied from 6.6 to $10.5 \%$ among recombinant lines (Fig. 6). We observed up to $44.2 \%$ increase in oleic 
Table 1 Oil and protein content estimated at $5 \%$ of moisture in recombinant lines and parents

\begin{tabular}{|c|c|c|c|c|c|c|}
\hline \multirow[t]{2}{*}{ Genotype } & \multicolumn{3}{|l|}{ Oil (\%) } & \multicolumn{3}{|l|}{ Protein $(\%)$} \\
\hline & 2013 rainy & 2013 post rainy & Pooled & 2013 rainy & 2013 post rainy & Pooled \\
\hline HOP-IL_MAs-108 & 53.3 & 56.8 & 55.1 & 24.3 & 23.1 & 23.7 \\
\hline HOP-IL_MAs-109 & 57.2 & 55 & 56.1 & 24.1 & 23.8 & 24.0 \\
\hline HOP-IL_MAS-111 & 52.4 & 56 & 54.2 & 23.8 & 22.4 & 23.1 \\
\hline HOP-IL_MAS-116 & 49.7 & 49.3 & 49.5 & 22.4 & 23.1 & 22.8 \\
\hline HOP-IL_MAs-119 & 56.3 & 46.2 & 51.2 & 23.6 & 21.0 & 22.3 \\
\hline HOP-IL_MAs-120 & 50.5 & 55.6 & 53.1 & 21.8 & 21.7 & 21.8 \\
\hline HOP-IL_MAs-123 & 52.4 & 51.3 & 51.9 & 25.6 & 24.4 & 25.0 \\
\hline HOP-IL_MAs-125 & 53.7 & 55.6 & 54.7 & 23.4 & 23.4 & 23.4 \\
\hline HOP-IL_MAs-130 & 54.8 & 54.6 & 54.7 & 21.7 & 22.1 & 21.9 \\
\hline HOP-IL_MAs-138 & 52.5 & 55.5 & 54 & 23.9 & 23.3 & 23.6 \\
\hline HOP-IL_MAS-144 & 53.7 & 54.1 & 53.9 & 23.3 & 21.2 & 22.2 \\
\hline HOP-IL_MAs-145 & 51.8 & 57.2 & 54.5 & 21.5 & 21.2 & 21.4 \\
\hline HOP-IL_MAS-154 & 52.6 & 54.5 & 53.5 & 22.9 & 23.1 & 23.0 \\
\hline HOP-IL_MAs-163 & 52.7 & 52.5 & 52.6 & 23.6 & 22.5 & 23.1 \\
\hline HOP-IL_MAs-164 & 51.5 & 55.7 & 53.6 & 24.0 & 24.6 & 24.3 \\
\hline HOP-IL_MAs-166 & 57.9 & 57.6 & 57.7 & 22.8 & 23.0 & 22.9 \\
\hline HOP-IL_MAs-171 & 53.3 & 52.5 & 52.9 & 23.0 & 23.6 & 23.3 \\
\hline HOP-IL_MAs-172 & 50.9 & 45 & 48 & 22.1 & 22.6 & 22.3 \\
\hline HOP-IL_MAs-181 & 51.6 & 50.4 & 51 & 22.6 & 22.7 & 22.6 \\
\hline HOP-IL_MAs-191 & 53.2 & 53.1 & 53.2 & 21.3 & 21.2 & 21.2 \\
\hline HOP-IL_MAs-201 & 57.2 & 46.3 & 51.8 & 22.4 & 20.8 & 21.6 \\
\hline ICGV 05141 & 55.1 & 54.3 & 54.7 & 24.6 & 25.5 & 25.0 \\
\hline SunOleic 95R & 50.9 & 50.4 & 50.6 & 25.1 & 27.2 & 26.2 \\
\hline Mean & 53.3 & 53.0 & 53.2 & 23.2 & 22.9 & 23.1 \\
\hline SE mean & 1.42 & 1.56 & 1.19 & 1.27 & 1.18 & 1.14 \\
\hline $\mathrm{CD}(0.05 \%)$ & 4.04 & 4.45 & 3.38 & 3.62 & 3.38 & 3.25 \\
\hline $\mathrm{CV} \%$ & 4.61 & 5.1 & 3.87 & 9.51 & 8.94 & 8.56 \\
\hline
\end{tabular}

acid, while up to $89 \%$ and $39.06 \%$ decrease in linoleic and palmitic acid, respectively, in recombinant lines, as compared to ICGV 05141 (Table 2). Furthermore, these three fatty acids constituted $\sim 90 \%$ of total fat composition, and palmitic acid content remained almost constant (in between 6\% and 10\%) in recombinant lines and parents. Indeed peanut genotypes with both high oleic acid and high oleic to linoleic acid $(\mathrm{O} /$ $\mathrm{L})$ ratio are more desirable. We observed $\mathrm{O} / \mathrm{L}$ ratio of 15.8 in SunOleic 95R and 2.4 in ICGV 05141, while it varied from 2.5 to 30.9 in recombinant lines. Out of which nine lines (HOP-IL_MAS-111, HOP-IL_MAS116, HOP-IL_MAS 119 , HOP-IL_MAS-130, HOPIL_MAS-138, HOP-IL_MAS-145, HOP-IL_MAS-172,
HOP-IL_MAS-191, HOP-IL_MAS-201) had O/L ratio more than 15.8 along with $\sim 80 \%$ oleic acid content (Fig. 7).

Pod yield

Pooled pod yield/plot was $1453 \mathrm{~kg}$ and $1323 \mathrm{~kg}$ in ICGV 05141 and GG 20, respectively, while it varied from 722 to $2151 \mathrm{~kg}$ among recombinant lines. Wide variation in pod yield was observed between genotypes as well as seasons. Significant yield superiority over female parent was observed in five recombinant lines (HOP-IL_MAS-130, HOP-IL_MAS-145, HOPIL_MAS-163, HOP-IL_MAS-181 and HOP-IL_MAS- $^{-}$ 
Fig. 4 Oleic, linoleic and palmitic acid content in recombinant lines and parents during 2013 rainy season
Fig. 5 Oleic, linoleic and palmitic acid content in recombinant lines and parents during 2013 post rainy season
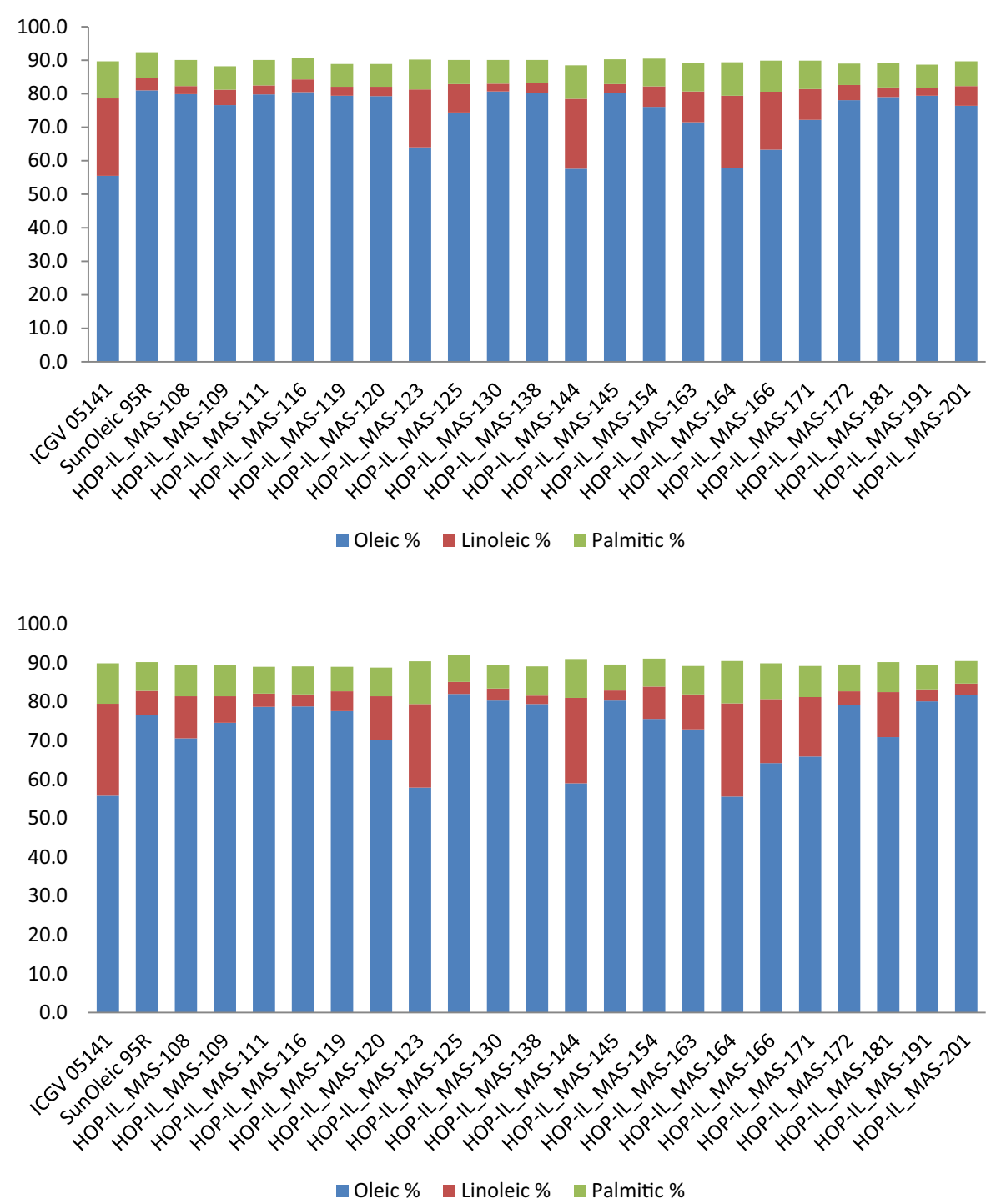

191) (Table 3). Besides, additional five recombinant lines (HOP-IL_MAs-116, HOP-IL_MAs-144, HOP$\mathrm{IL}_{-\mathrm{MAS}}-171$, HOP-IL_MAS-172 and HOP-IL_MAS201) yielded at par with the female parent. Indeed, these 10 recombinant lines had yield superiority over GG 20. There was no significant difference in shelling percent between ICGV 05141 (68\%) and GG 20 (66\%), while it varied from 65 to $74 \%$ among recombinant lines.

Recombinant lines having superior or at par pod yield with ICGV 05141 also had superior or at par shelling percent with female parent except HOPIL_MAs-181 which had $65 \%$ shelling percent. Similarly, no significant variation in hundred kernel weight was observed between ICGV 05141 (38 g) and GG 20 $(39 \mathrm{~g})$, while it varied from 26 to $39 \mathrm{~g}$ among recombinant lines (Table 3).

Passport data of high oleate genotype

ICGV 05141 is a Virginia bunch genotype with decumbent-3 growth habit; alternate branching; dark green colour ovate shape leaf and simple inflorescence. The genotype produces 50\% flowering at 26 days after germination and matures in 120 days. Average plant height is $36.0 \mathrm{~cm}$; produces average six primary branches/plant and two to three flowers/ inflorescence. Average leaflet length and width are 
Fig. 6 Oleic, linoleic and palmitic acid content in recombinant lines and parents pooled over 2013 rainy and 2013 post rainy seasons

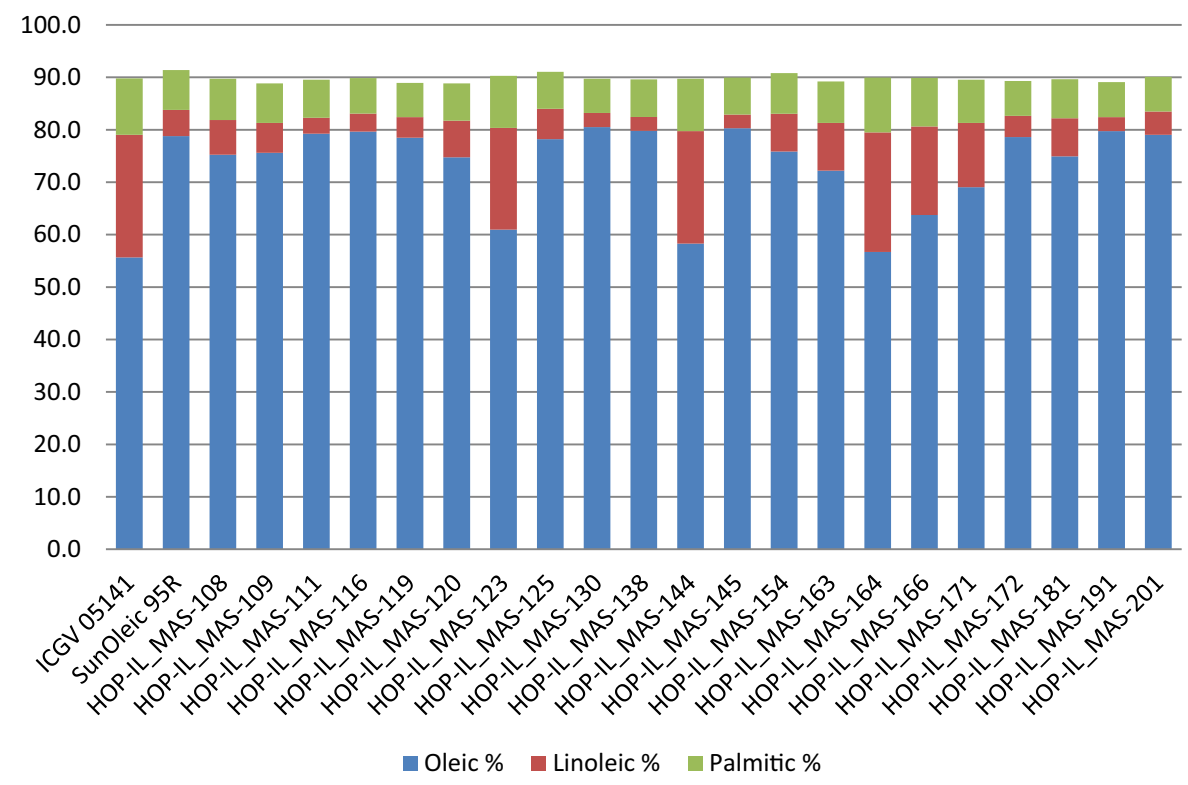

$36.6 \mathrm{~mm}$ and $14.6 \mathrm{~mm}$, respectively. Pods are mostly two seeded and average length and width of pods are $36.6 \mathrm{~mm}$ and $26.0 \mathrm{~mm}$, respectively. Kernels are rose in colour, and average length and width of kernels are $28.0 \mathrm{~mm}$ and $16.0 \mathrm{~mm}$, respectively (Fig. 8). It yields $202.0 \mathrm{~g}$ of pods per square meter area with $32 \%$ harvest index, 70\% shelling, hundred kernels weight of $38 \mathrm{~g}, \sim 55 \%$ oil content and $\sim 55.7 \%$ oleic acid content. All the recombinant lines developed under this study were Virginia bunch in growth habit. For qualitative traits, not much variation was observed between recombinant line and female parent. However, moderate to wide variation was observed between recombinant line and female parent and between recombinant lines in terms of quantitative traits and special features. Recombinant lines mostly differed in days to maturity, plant height, leaflet size, pod size and kernel size; besides pod yield, shelling percent and 100-kernel weight. In case of two special features, majority of recombinant lines were in combination of high oil content similar to ICGV 05141 and high oleic acid content similar to SunOleic 95R which revealed the success of marker assisted selection (Supplementary Data).

\section{Discussion}

In general, high oleic peanuts are preferred by the stakeholders due to its enhanced shelf life and multiple health benefits. Hence, improvement of oleic acid content in peanut is one of the important breeding objective worldwide (Janila et al. 2016). The fatty acid desaturase enzyme catalyzes the conversion of oleic acid to linoleic acid, and is encrypted by $a h F A D 2 A$ and $a h F A D 2 B$ homeologous alleles (Jung et al. 2000a, b; Yu et al. 2008). Both the $a h F A D 2$ alleles have $99 \%$ sequence homology (Jung et al. 2000a; Lopez et al. 2000) and inactivation of both the alleles stops conversion of oleic acid to linoleic acid, causing increased accumulation of oleic acid in peanut (Jung et al. 2000a, b). Development of molecular markers linked to ahFAD2 genes has expedited the breeding high oleic acid content peanut more precisely in much shorter time and resources. Moreover, MABC breeding ensures transfer of desired gene/QTL keeping the other features of the female parent intact (Pandey et al. 2012; Varshney et al. 2013). Previously, nematode resistance (Simpson et al. 2003a), high oleic acid content (Chu et al. 2011; Janila et al. 2016) and rust resistance (Varshney et al. 2014) were transferred to elite peanut cultivars through molecular breeding. Transfer of high oleate trait into popular peanut genotypes has been achieved using both conventional and molecular breeding. The F435, a mutant with $80 \%$ 
Table 2 Change in oleic acid, linoleic acid and palmitic acid content in recombinant lines with respect to ICGV 05141

\begin{tabular}{|c|c|c|c|c|c|c|}
\hline Recombinant line & $\begin{array}{l}\text { Oleic } \\
\text { acid \% }\end{array}$ & $\begin{array}{l}\% \text { increase in } \\
\text { oleic acid }\end{array}$ & Linoleic acid \% & $\begin{array}{l}\% \text { decrease in } \\
\text { linoleic acid }\end{array}$ & $\begin{array}{l}\text { Palmitic } \\
\text { acid } \%\end{array}$ & $\begin{array}{l}\% \text { decrease in } \\
\text { palmitic acid }\end{array}$ \\
\hline HOP-IL_MAs ${ }^{-108}$ & 75.3 & 35.1 & 6.6 & 72 & 7.9 & 0.4 \\
\hline HOP-IL_MAS-109 & 75.6 & 35.7 & 5.7 & 76 & 7.6 & 0.4 \\
\hline HOP-IL_MAS-111 & 79.3 & 42.3 & 3.1 & 87 & 7.3 & 0.5 \\
\hline HOP-IL_MAS-116 & 79.7 & 43.0 & 3.5 & 85 & 6.8 & 0.5 \\
\hline HOP-IL_MAS-119 & 78.5 & 40.9 & 3.9 & 83 & 6.6 & 0.6 \\
\hline HOP-IL_MAS-120 & 74.8 & 34.2 & 7.0 & 70 & 7.1 & 0.5 \\
\hline HOP-IL_MAS-123 & 61.0 & 9.4 & 19.4 & 17 & 10.0 & 0.1 \\
\hline HOP-IL_MAS-125 & 78.2 & 40.4 & 5.8 & 75 & 7.1 & 0.5 \\
\hline HOP-IL_MAS-130 & 80.5 & 44.5 & 2.7 & 88 & 6.6 & 0.6 \\
\hline HOP-IL_MAS-138 & 79.8 & 43.3 & 2.7 & 89 & 7.2 & 0.5 \\
\hline HOP-IL_MAS-144 & 58.3 & 4.7 & 21.5 & 8 & 10.0 & 0.1 \\
\hline HOP-IL_MAS-145 & 80.3 & 44.2 & 2.6 & 89 & 7.1 & 0.5 \\
\hline HOP-IL_MAS-154 & 75.9 & 36.2 & 7.2 & 69 & 7.8 & 0.4 \\
\hline HOP-IL_MAs-163 & 72.2 & 29.6 & 9.1 & 61 & 7.9 & 0.4 \\
\hline HOP-IL_MAS-164 & 56.7 & 1.8 & 22.8 & 3 & 10.5 & 0 \\
\hline HOP-IL_MAS-166 & 63.8 & 14.5 & 16.9 & 28 & 9.3 & 0.2 \\
\hline HOP-IL_MAS-171 & 69.1 & 24.0 & 12.3 & 48 & 8.3 & 0.3 \\
\hline HOP-IL_MAS-172 & 78.6 & 41.1 & 4.1 & 83 & 6.7 & 0.5 \\
\hline HOP-IL_MAS-181 & 75.0 & 34.6 & 7.3 & 69 & 7.5 & 0.4 \\
\hline HOP-IL_MAS-191 & 79.8 & 43.2 & 2.7 & 89 & 6.7 & 0.5 \\
\hline HOP-IL_MAS-201 & 79.1 & 41.9 & 4.5 & 81 & 6.6 & 0.6 \\
\hline ICGV 05141 & 55.7 & 0 & 23.4 & 0 & 10.8 & 0 \\
\hline
\end{tabular}

oleic acid content was the primary source for high oleate trait (Norden et al. 1987) and subsequently high oleate peanut lines such as, SunOleic 95R (Gorbet and Knauft 1997) and Tamrun OL01 (Simpson et al. 2003b) were developed using F435 through conventional breeding methods. Chu et al. $(2007,2009)$ first developed the molecular markers for $a h F A D 2$ genes and used them for increasing the high oleate trait in peanut using molecular breeding (Chu et al. 2011; Janila et al. 2016). Both CAPS and SNP markers, linked to high oleic acid content, were used to transfer the mutant alleles. Further selected lines were confirmed by HybProbeSNP assay (Bernard et al. 1998). In a separate study, Mienie and Pretorius (2013) selected heterozygous and homozygous lines for both the mutant alleles using multiplex real-time PCR assay, developed by Barkley et al. (2010). Thus, above studies showed that linked marker could be conveniently used to identify plants, carrying mutant alleles, in early generations of breeding program aimed at increasing oleic acid content. Furthermore, the time and the volume of breeding material in segregating generations reduced considerably. In our study ICGV 05141, a high oil containing peanut genotype, was targeted for improving its oil quality using marker assisted selection. Selection of breeding lines with desirable oil content and high oleic acid content was carried out by genotyping in early generations and phenotyping in advanced generations. Genotypingbased selection was done in early generations, to confirm plants with desirable genomic region. Subsequently, desirable lines were phenotyped in $\mathrm{F}_{4}$ and $\mathrm{F}_{5}$ generations for confirmation. High oil content and high oleic acid content peanuts are most suitable for oil industry to produce higher oil production along with improved oil quality. Furthermore, increased shelf-life and health benefits of food products made from high oleic peanuts are boon to all the stake holders including consumers. In this study we developed high oleic acid and oil content recombinants 
Fig. 7 Oleic to linoleic acid ratio in recombinant lines and parents pooled over 2013 rainy and 2013 post rainy seasons

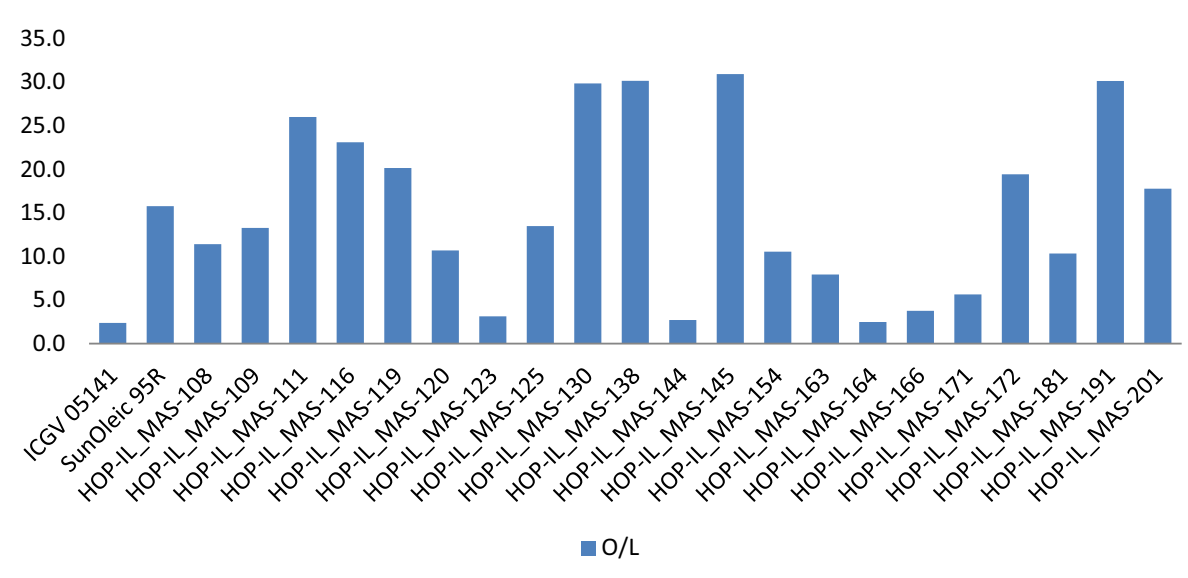

using marker-assisted breeding. Realizing the importance of oil content for Indian consumers, the high oil content feature of the female parent has been successfully retained in majority of the recombinant lines. Furthermore, back ground selection with selected SSRs revealed the development of ideal recombinants carrying genomic region of female parent adjacent to $a h F A D 2$ loci along with high oleic acid as well as high oil content. Thus, we successfully transferred the high oleic acid content from SunOleic 95R in the genetic background of ICGV 05141, which resulted in development of recombinants of ICGV 05141 with high oleic acid. Up to $44 \%$ increase in oleic acid content was observed in the recombinant lines as compared to ICGV 05141. The increase in oleic acid content in recombinant lines simultaneously reduced the levels of linoleic acid. This was due to mutation in both the ahFAD2 loci resulting in less/no production of fatty acid desaturase enzyme which stopped conversion of oleic acid to linoleic acid. Reduced linoleic and palmitic acid contents have additional health benefits to the consumers. However, so far available studies or data do not allow determination of the level of dietary linoleic acid needed for optimum health (Jandacek 2017). Linoleic acid in recombinant lines decreased up to $89 \%$ as compared to female parent. Similarly, palmitic acid in recombinant lines decreased up to $0.6 \%$ as compared to female parent. Thus, low linoleic acid and low palmitic acid traits have also been introgressed from SunOleic 95R. Studies concerning high oleic acid have mostly focused on the levels of oleic acid and linoleic acid in the recombinant lines. Very often it was observed that the change in one metabolite brought about by a change in the corresponding enzyme in a biosynthetic pathway, affected the levels of all other metabolites in the pathway. Earlier studies by Pandey et al. (2012) and Wang et al. (2015b) illustrated the effect of ahfad2 alleles on palmitic acid levels. Here, we also observed significant reduction in palmitic acid simultaneously with the increase in oleic acid content in recombinant lines due to introgression of $a h f a d 2$ alleles. Moreover, oil, oleic acid, linoleic acid and palmitic acid contents traits are quantitative in nature and would vary with the change in environments (Sarvamangala et al. 2011). The variation observed here in oil content among recombinant lines could be due to genotype $\times$ environmental interactions. Besides, Knauft et al. (1993) and Moore and Knauft (1989) reported that inheritance of high-oleate trait in F-435 mutant is controlled by two recessive genes. Later, Isleib et al. (1996) reported that oleic acid content in Virginia peanut was controlled by two loci but with modifiers and additional epistatic interactions. This could be one of the possible reason for variation in oleic acid (56 to $80 \%$ ) content in recombinant lines.

Yield superiority and yield stability of a genotype over environments are two key parameters of a successful variety (Allard 1960). The genotypic selection combined with phenotypic selection was found effective in selecting recombinant lines with target traits, desired plant features and agronomic value. The recombinant lines were initially selected by genotyping and later tested for phenotypic traits, biochemical parameters, and yield. Selected 10 recombinant lines yielded either significantly higher or at par with female parent. Moreover, shelling percent and hundred-kernel weight of these recombinant lines were also either higher or at 


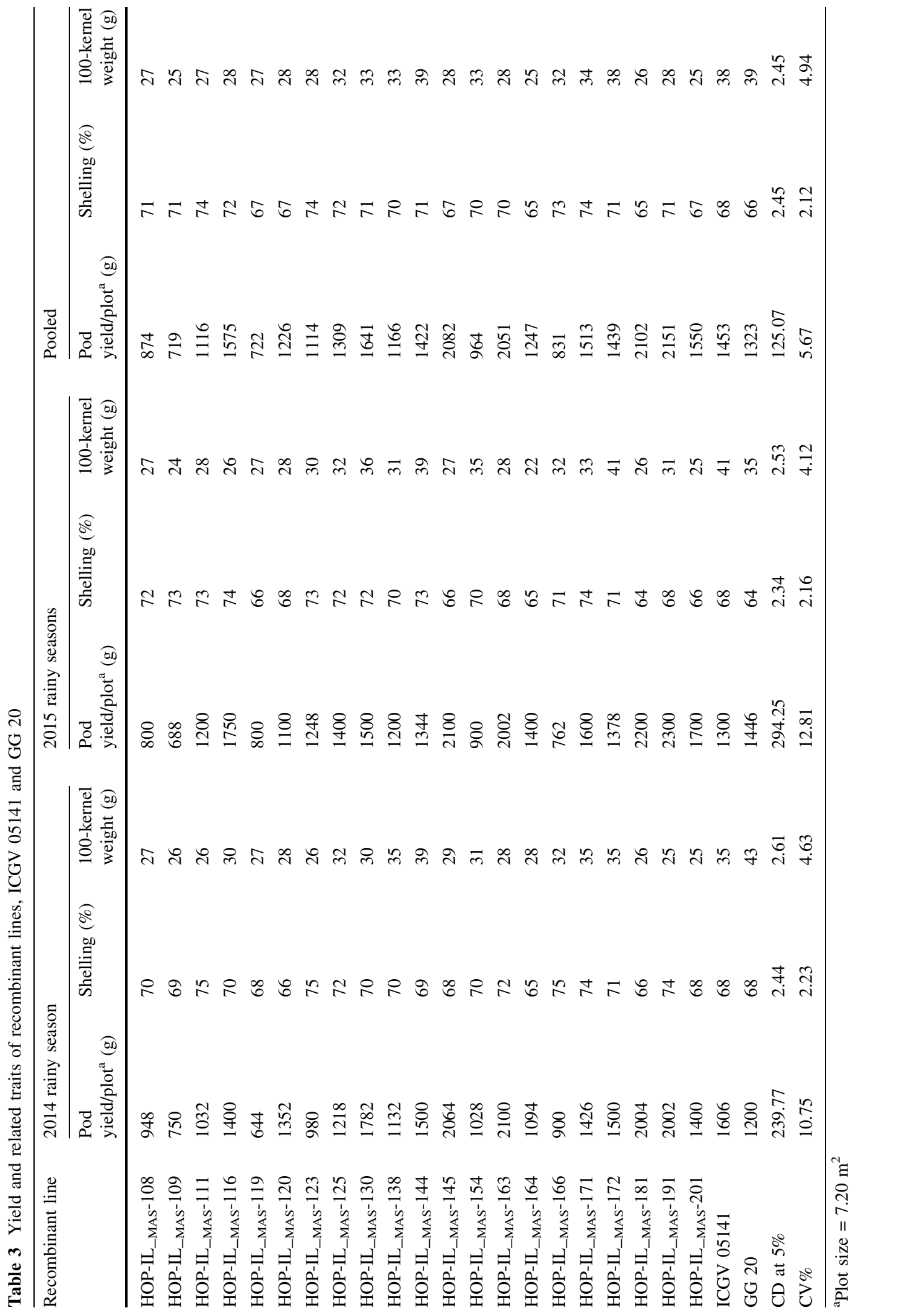



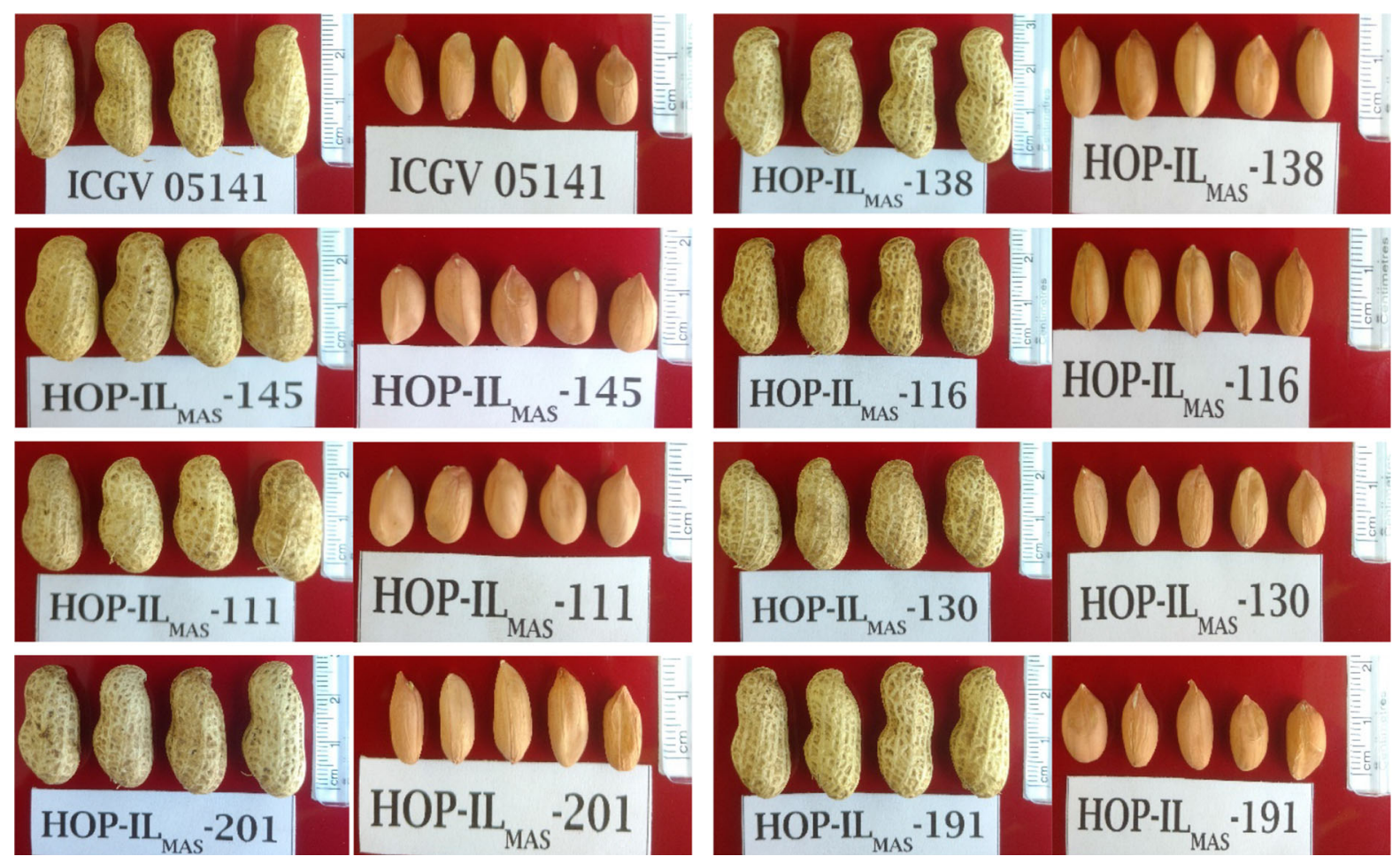

Fig. 8 Pods and kernels of selected high oleic content recombinant lines and ICGV 05141 showing variation in shape and size

par with the female parent. Besides, passport data reiterates that qualitative and quantitative traits of recombinant lines and ICGV 05141 did not vary much except oleic acid content. Thus, recombinant lines, bred here using marker assisted selection by cutting huge resources and time, would be high yielding peanut cultivar(s) with high oil and high oleic acid content to the peanut farmers of India.

\section{Conclusion}

Peanut with desirable fatty acid composition is key for sustaining the demand of consumers and traders in coming years realizing the tough competition from other oil crops. India being the second largest peanut producer holds great market potential of high oil and oleic peanut and therefore, we developed recombinants of ICGV 05141 with high oleic acid besides high oil, pod yield and yield related traits devoid of much time and resources. These recombinant lines will certainly extend additional economic benefits to the Indian farmers in addition to ensuring availability of high oleic peanuts to the traders and industry vis-à-vis peanut oil and other food products with extended shelf life and additional health benefits to the consumers.

Acknowledgements Authors acknowledge the financial support received vide no. 11-2/2010-Pul (TMOP), Govt. of India, Ministry of Agriculture, Department of Agriculture and Cooperation.

\section{Compliance with ethical standards}

Conflict of interest The authors declare that they have no conflict of interest.

\section{References}

Allard RW (1960) Principles of plant breeding. Willey, New York

Barkley NA, Chamberlin KDC, Wang ML, Pittman RN (2010) Development of a real-time PCR genotyping assay to identify high oleic acid peanuts (Arachis hypogaea L.). Mol Breed 25(3):541-548. https://doi.org/10.1007/ s11032-009-9338-Z

Bera SK, Kamdar JH, Kasundra SV, Ajay BC (2016) Identification of a novel QTL governing resistance to sclerotial stem rot disease in peanut. Australas Plant Pathol 45(6):637-644. https://doi.org/10.1007/s13313-016-0448-x 
Bernard PS, Lay MJ, Wittwer CT (1998) Integrated amplification and detection of the C677T point mutation in the methylene tetrahydrofolate reductase gene by fluorescence resonance energy transfer and probe melting curves. Anal Biochem 255(1):101-107. https://doi.org/10.1006/abio. 1997.2427

Chen Z, Wang ML, Barkley NA, Pittman RN (2010) A simple allele-specific PCR assay for detecting $F A D 2$ alleles in both $\mathrm{A}$ and $\mathrm{B}$ genomes of the cultivated peanut for higholeate trait selection. Plant Mol Biol Rep 28:542-548. https://doi.org/10.1007/s11105-010-0181-5

Chu Y, Ramos L, Holbrook CC, Ozias-Akins P (2007) Frequency of a loss-of-function mutation in Oleoyl-PC Desaturase $(a h F A D 2 A)$ in the mini-core of the us peanut germplasm collection. Crop Sci 47(6):2372-2378. https://doi.org/10. 2135/cropsci2007.02.0117

Chu Y, Holbrook CC, Ozias-Akins P (2009) Two alleles of control the high oleic acid trait in cultivated peanut. Crop Sci 49(6):2029-2036. https://doi.org/10.2135/cropsci2009.01. 0021

Chu Y, Wu CL, Holbrook CC, Tillman BL, Person G, OziasAkins P (2011) Marker-assisted selection to pyramid nematode resistance and the high oleic trait in peanut. Plant Genome 4(2):110-117. https://doi.org/10.3835/plantge nome2011.01.0001

FAOSTAT (2014). http://faostat.fao.org. Accessed 12 Apr 2018

Gautami B, Foncéka D, Pandey MK, Moretzsohn MC, Sujay V, Qin H, Hong Y, Faye I, Chen X, BhanuPrakash A, Shah TM, Gowda MV, Nigam SN, Liang X, Hoisington DA, Guo B, Bertioli DJ, Rami JF, Varshney RK (2012) An international reference consensus genetic map with 897 marker loci based on 11 mapping populations for tetraploid groundnut (Arachis hypogaea L.). PLoS ONE 7:41213

Gorbet DW, Knauft DA (1997) Registration of 'SunOleic 95R' peanut. Crop Sci 37(4):1392

IBPGR and ICRISAT (1992) Descriptors for groundnut, 125. International Board for Plant Genetic Resources, Rome and International Crops Research Institute for the Semi-Arid Tropics, Andhra Pradesh. ISBN 92-9043-139-3

IRRI. International Rice Research Institute (2007) Crop Stat for Windows version 7(2), 2007, 3. International Rice Research Institute, Manila

Isleib TG, Young CT, Knauft DA (1996) Fatty acid genotypes of five virginia-type cultivars. Crop Sci 36:556-558

Jandacek RJ (2017) Linoleic acid: a nutritional quandary. In: Parthasarathy S (ed) Healthcare 5(2):25. https://doi.org/10. 3390/healthcare5020025

Janila P, Pandey MK, Shasidhar Y, Variatha MT, Sriswathi M, Khera P, Manohar SS, Nagesh P, Vishwakarma MK, Mishra GP, Radhakrishnan T, Manivannan N, Dobariya KL, Vasanthi RP, Varshney RK (2016) Molecular breeding for introgression of fatty acid desaturase mutant alleles ( $a h F A D 2 A$ and $a h F A D 2 B$ ) enhances oil quality in high and low oil containing peanut genotypes. Plant Sci 242: 203-213. https://doi.org/10.1016/j.plantsci.2015.08.013

Johnson S, Saikia N (2008) Fatty acids profile of edible oils and fat in India. Centre for Science and Environment, New Delhi, pp 1-48

Jung S, Swift D, Sengoku E, Patel M, Teule F, Powell G, Moore $\mathrm{K}$, Abbott A (2000a) The high oleate trait in the cultivated peanut (Arachis hypogaea L.) I. Isolation and characterization of two genes encoding microsomal oleoylPC desaturases. Mol Gen Genet 263(5):796-805. https:// doi.org/10.1007/s004380000244

Jung S, Powell G, Moore K, Abbott A (2000b) The high oleate trait in the cultivated peanut (Arachis hypogaea L.). II. Molecular basis and genetics of the trait. Mol Gen Genet 263(5):806-811. https://doi.org/10.1007/s004380000243

Kavera B, Nadaf HL, Hanchinal RR (2014) Near infrared reflectance spectroscopy (NIRS) for large scale screening of fatty acid profile in peanut (Arachis hypogaea L.). Legume Res 37(3):272-280

Knauft DA, Moore K, Gorbet DW (1993) Further studies on the inheritance of fatty acid composition in peanut. Peanut Sci 20:74-76

Kratz M, Cullen P, Kannenberg F, Kassner A, Fobker M, Abuja PM, Assmann G, Wahrburg U (2002) Effects of dietary fatty acids on the composition and oxidizability of low density lipoprotein. Eur J Clin Nutr 56:72-81. https://doi. org/10.1038/sj.ejen.1601288

Lopez Y, Nadaf HL, Smith OD, Connell JP, Reddy AS, Fritz AK (2000) Isolations and characterization of the $\Delta 12$ fatty acid desaturase in peanut (Arachis hypogaea L.) and search for polymorphism for the high oleate trait in Spanish markettype lines. Theor Appl Genet 101:1131-1138. https://doi. org/10.1007/s001220051589

Mace ES, Buhariwalla KK, Buhariwalla HK, Crouch JH (2003) A high-throughput DNA extraction protocol for tropical molecular breeding programs. Plant Mol Biol Rep 21(4):459-460. https://doi.org/10.1007/BF02772596

Mienie CMS, Pretorius AE (2013) Application of marker-assisted selection for $a h F A D 2 A$ and $a h F A D 2 B$ genes governing the high-oleic acid trait in South African groundnut cultivars (Arachis hypogaea L.). Afr J Biotechnol 12(27):4283-4289. https://doi.org/10.5897/AJB2012.2976

Misra JB, Mathur RS (1998) A simple and economic procedure for transmethylation of fatty acids of groundnut oil for analysis by GLC. Int Arachis Newslett 18:40-42

Moore KM, Knauft DA (1989) The inheritance of high oleic acid in peanut. J Hered 80(3):252-253

Mozingo RW, O'keefe SF, Sanders TH, Hendrix KW (2004) Improving shelf life of roasted and salted in shell peanuts using high oleic fatty acid chemistry. Peanut Sci 31(1):40-45. https://doi.org/10.3146/pnut.31.1.0009

Norden AJ, Gorbet DW, Knauft DA, Young CT (1987) Variability in oil quality among peanut genotypes in the Florida breeding program. Peanut Sci 14(1):7-11. https://doi.org/ 10.3146/i0095-3679-14-1-3

O'Byrne DJ, Knauft DA, Shireman RB (1997) Low fat-monounsaturated rich diets containing high-oleic peanuts improve serum lipoprotein profiles. Lipids 32(7):687-695. https://doi.org/10.1007/s11745-997-0088-y

O'keefe SF, Wiley VA, Knauft DA (1993) Comparison of oxidative stability of high-and normal-oleic peanut oils. J Am Oil Chem Soc 70(5):489-492. https://doi.org/10. 1007/BF02542581

Pandey MK, Monyo E, Ozias-Akins P, Liang X, Guimarães P, Nigam SN, Upadhyaya HD, Janila P, Zhang X, Guo B, Cook DR, Bertioli DJ, Michelmore R, Varshney RK (2012) Advances in Arachis genomics for peanut improvement. Biotechnol Adv 30(3):639-651. https://doi.org/10.1016/j. biotechadv.2011.11.001 
Rizzo WB, Watkins PA, Phillips MW, Cranin D, Campbell B, Avigan J (1986) Adre-noleukodystrophy Oleic acid lowers fibroblast saturated C22-26 fatty acids. Neurology 36(3):357-361. https://doi.org/10.1212/WNL.36.3.357

Sarvamangala C, Gowda MVC, Varshney RK (2011) Identification of quantitative trait loci for protein content, oil content and oil quality for groundnut (Arachis hypogaea L.). Field Crops Res 122(1):49-59. https://doi.org/10. 1016/j.fcr.2011.02.010

Simpson CE, Baring MR, Schubert AM, Melouk HA, Black MC, Lopez Y, Keim KA (2003a) Registration of 'Tamrun OL01' peanut. Crop Sci 43(6):2298

Simpson CE, Starr JL, Church GT, Burow MD, Paterson AH (2003b) Registration of 'NemaTAM' peanut. (Registrations of cultivars). Crop Sci 43(4):1561

Varshney RK, Mohan SM, Gaur PM, Gangarao NVPR, Pandey MK, Bohra A, Sawargaonkar SL, Chitikineni A, Kimurto PK, Janila P, Saxena KB, Fikre A, Sharma M, Rathore A, Pratap A, Tripathi S, Datta S, Chaturvedi SK, Mallikarjuna N, Anuradha G, Babbar A, Choudhary AK, Mhase MB, Bharadwaj CH, Mannur DM, HarerPN Guo B, Liang X, Nadarajan N, Gowda CL (2013) Achievements and prospects of genomics-assisted breeding in three legume crops of the semi-arid tropics. Biotechnol Adv 31(8):1120-1134. https://doi.org/10.1016/j.biotechadv.2013.01.001

Varshney RK, Pandey MK, JanilaP Nigam SN, Sudini H, Gowda MVC, Sriswathi M, Radhakrishnan T, Manohar SS, Nagesh P (2014) Marker-assisted introgression of a QTL region to improve rust resistance in three elite and popular varieties of peanut (Arachis hypogaea L.). Theor Appl Genet 127(8):1771-1781. https://doi.org/10.1007/s00122014-2338-3

Vassiliou EK, Gonzalez A, Garcia C, Tadros JH, Chakraborty G, Toney JH (2009) Oleic acid and peanut oil high in oleic acid reverse the inhibitory effect of insulin production of the inflammatory cytokine TNF-alpha both in vitro and in vivo systems. Lipids Health Dis 8:25. https://doi.org/10. 1186/1476-511X-8-25

Wang CT (2009) Peanut production, trade and utilization peanut science and technology bull. Natl Peanut Agric Ind Res Sys 1(5\&6):8-32

Wang ML, Chen CY, Tonnis B, Barkley NA, Pinnow DL, Pittman RN, Davis J, Holbrook CC, Stalker HT, Pederson GA (2013) Oil, fatty acid, flavonoid, and resveratrol content variability and $F A D 2 A$ functional SNP genotypes in the US peanut mini-core collection. J Agric Food Chem 61(11):2875-2882. https://doi.org/10.1021/jf305208e

Wang ML, Khera P, Pandey MK, Wang H, Qiao L, Feng S, Tonnis B, Barkley NA, Pinnow D, Holbrook CC, Culbreath AK, Varshney RK, Guo B (2015a) Genetic mapping of QTLs controlling fatty acids provided insights into the genetic control of fatty acid synthesis pathway in peanut (Arachis hypogaea L.). PLoS ONE 10(4):e0119454. https://doi.org/10.1371/journal.pone.0119454

Wang XZ, Wu Q, Tang YY, Sun QX, Wang CT (2015b) FAD2B from a peanut mutant with high oleic acid content was not completely dysfunctional. Adv Appl Biotechnol 332:265271. https://doi.org/10.1007/978-3-662-45657-6_28

WHO (2003) Diet, nutrition and the prevention of chronic diseases, WHO technical report series 916, Report of a joint WHO/FAO expert consultation. World Health Organization, Geneva, p 88

Yamaki T, Nagamine I, Fukumoto K, Yano T, Miyahara M, Sakurai H (2005) High oleic peanut oil modulates promotion stage in lung tumorigenesis of mice treated with methyl nitrosourea. Food Sci Technol Res 11(2):231-235. https://doi.org/10.3136/fstr.11.231

Yu S, Pan L, Yang Q, Min P, Ren Z, Zhang H (2008) Comparison of the delta 12 fatty acid desaturase gene between high-oleic and normal-oleic peanut genotypes. J Genet Genomics 35(11):679-685. https://doi.org/10.1016/S16 73-8527(08)60090-9 